n. ${ }^{\circ} 1$

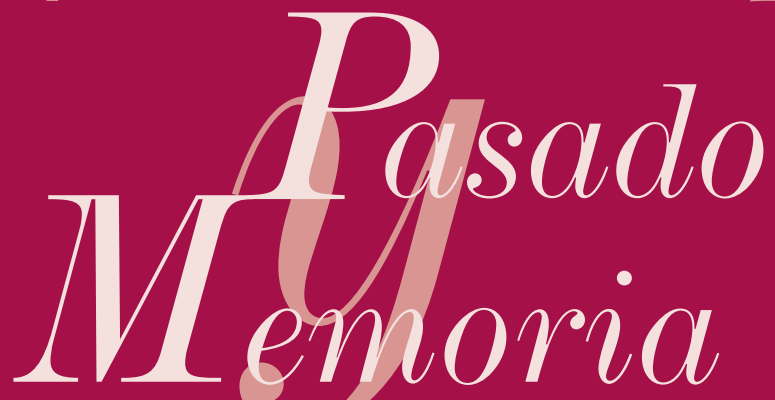

Revista de Historia Contemporánea

Instituciones y sociedad en el franquismo

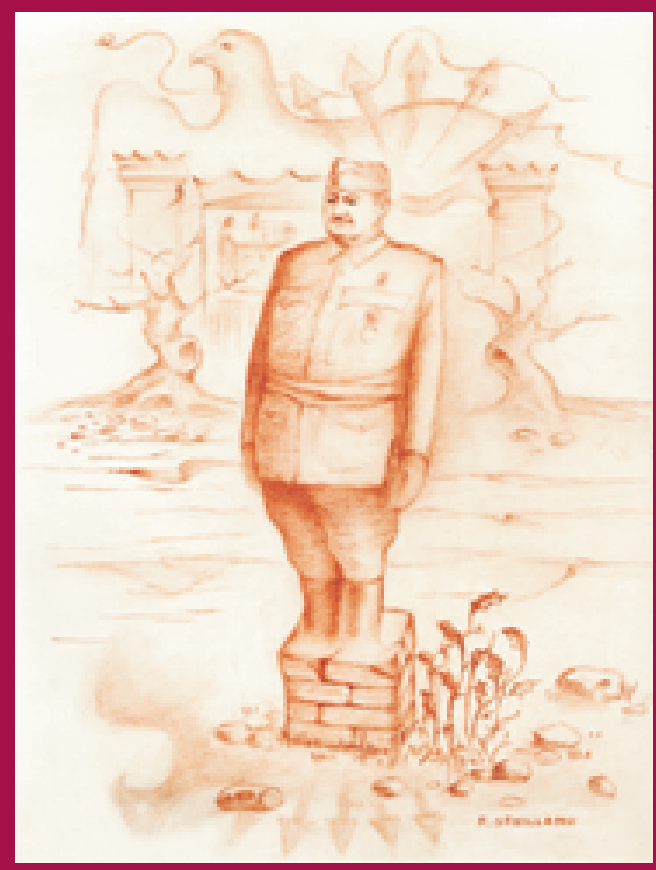




\section{Dirección: Glicerio Sánchez Recio}

Secretaría: Francisco Sevillano Calero

Consejo de redacción: Salvador Forner Muñoz, Rosa Ana Gutiérrez Lloret, Emilio La Parra López, Roque Moreno Fonseret, Mónica Moreno Seco, José Miguel Santacreu Soler, Rafael Zurita Aldeguer

Consejo asesor:
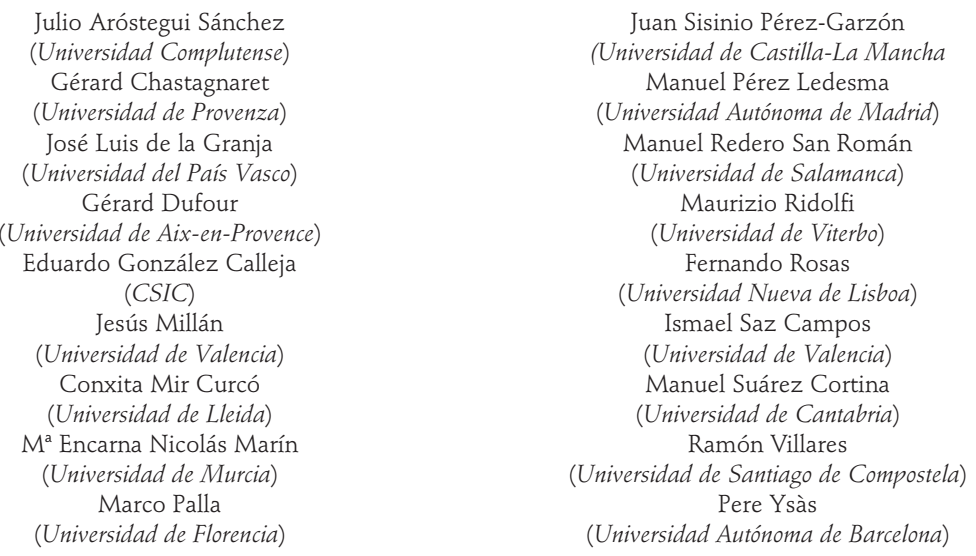

Coordinación del monográfico: Glicerio Sánchez Recio

Ilustración de la portada: El despropósito, por Francisco Sevillano Bonillo

\begin{tabular}{|c|c|c|c|}
\hline Edita: & $\begin{array}{l}\text { Departamento de Humanidades Contemporáneas } \\
\text { Área de Historia Contemporánea } \\
\text { Facultad de Filosofía y Letras } \\
\text { Universidad de Alicante } \\
\text { Apartado Postal } 99 \\
03080 \text { Alicante }\end{array}$ & Distribución: & $\begin{array}{l}\text { Publicaciones } \\
\text { Universidad de Alicante } \\
\text { Apartado Postal } 99 \\
03080 \text { Alicante }\end{array}$ \\
\hline
\end{tabular}

Composición: Espagrafic

Impresión: INGRA Impresores

Depósito legal: A-293-2002

ISSN: 1579-3311

Reservados todos los derechos. No se permite reproducir, almacenar en sistemas de recuperación de la información ni transmitir alguna parte de esta publicación, cualquiera que sea el medio empleado -electrónico, mecánico, fotocopia, grabación, etc.-, sin el permiso previo de los titulares de los derechos de la propiedad intelectual.

\section{Estos créditos pertenecen a la edición impresa de la obra}

Edición electrónica:

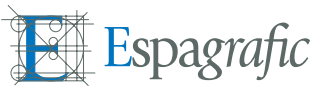




\author{
J. Alberto Gómez Roda
}

\title{
PERCEPCIONES DE LAS INSTITUCIONES \\ Y ACTITUDES POLÍTICAS DE LA SOCIEDAD EN LA POSGUERRA
}


Portada

Créditos

PERCEPCIONES DE LAS INSTITUCIONES Y ACTITUDES POLÍTICAS DE LA SOCIEDAD EN LA POSGUERRA $\ldots \ldots \ldots \ldots \ldots \ldots$

Los documentación de las percepciones de las instituciones de posguerra en Valencia . . . . . . 9 Represión y control social . . . . . . . . . . . 12 Política y administración $\ldots \ldots \ldots \ldots \ldots 17$ Consumo y producción $\ldots \ldots \ldots \ldots 22$ Trabajo y condiciones laborales . . . . . . . . . 34 La escuela y la socialización fascista y católica . . . 40 Jóvenes, ocio y sociabilidad . . . . . . . . 46 46 Notas . . . . . . . . . . . . . . . . . . . . . 49 
Percepciones de las instituciones y actitudes políticas de la sociedad en la posguerra

\section{Percepciones de las instituciones y actitudes políticas de la sociedad en la posguerra}

J. Alberto Gómez Roda

[ "Nuevo Estado" franquista instauró en sus orígenes - jurisdicciones especiales, instituciones y organismos cuyo nombre ha quedado unido a la realidad de la posguerra española. Respondían a la voluntad de controlar, vigilar, regimentar, encuadrar e intervenir toda la actividad social, de la que participaron los pilares institucionales cardinales del régimen: el Ejército, la Iglesia católica y el partido FET-JONS con los sindicatos verticales. Abordamos aquí una aproximación a la percepción de estas instituciones franquistas por la población en los documentos escritos y orales. La provincia de Valencia es el marco que utilizamos para ello, aunque hacemos uso ocasional de documentos referidos a otros lugares (nota 1). Acabamos en vísperas de 1956, año de los disturbios estudiantiles de Madrid. La década de 1950 es para los economistas el "decenio bisagra" de la dic- 


\section{J. Alberto Gómez Roda}

tadura; podemos pensar que 1956 actúa como gozne sobre el que pivota el giro decisivo que entonces se produce. Si en 1951-52 prácticamente se ha desarticulado la oposición activa en el interior, termina el racionamiento y se inicia el desmantelamiento de la intervención autárquica, en 1956 se aprecian ya los efectos de la socialización en la dictadura de la nueva generación que toma el relevo a la que hizo la guerra civil.

La cuestión de la percepción de las instituciones del franquismo es una concreción de la problemática de las actitudes políticas de los españoles bajo la dictadura. Los historiadores que han estudiado las actitudes políticas en el franquismo insisten en la politización de una práctica institucional discriminatoria entre vencedores y vencidos. La evidencia más clara de ello se encontraría en la depuración política de la administración y de los colegios profesionales, en la exigencia de certificación sobre antecedentes políticos para cualquier trámite, e incluso en la parcialidad de la justicia ordinaria según el pasado político de los encausados. Habitualmente, esta discriminación tenía una vertiente clasista y clientelar no menos clara. El resultado sería lo que Ismael Saz ha llamado un "consenso negativo", marcado por 
Percepciones de las instituciones y actitudes políticas de la sociedad en la posguerra

la despolitización de percepciones y actitudes, cuando no por una claro "antipoliticismo" (nota 2).

La generación de posguerra se había formado bajo el dominio de una dictadura de inequívocos componentes fascistas y nacional-católicos. En 1978 Manuel Ramírez caracterizaba la mentalidad política de los españoles por el autoritarismo, la "despolitización y provocada apatía" asociada a un profundo escepticismo "hacia todo el sistema en sí (mundo sindical, agencias de burocracia estatal, sistemas de selección)", tanto como a una "histórica debilidad del sentimiento de moral cívica", manifiesta en el individualismo y la tolerancia e incluso reconocimiento de "una práctica de 'pancorrupción' en la que todo era bueno o malo según la 'categoría social' que lo hiciera" (nota 3 ).

La experiencia de la posguerra tendría mucho que ver con la construcción de una mentalidad política de este género. Nuestra tesis es que la politización que tuvo efectos despolitizadores en el conjunto de la sociedad, evidente al finalizar la década de 1940, fue distinta de la politización fascista. En la Italia mussoliniana, tanto como en la Alemania nazi, siguió a la toma del poder y a la represión política un movimiento reintegrador nacionalista que buscaba un sentido de pertenencia de los ciudadanos mediante una ficción participativa 


\section{J. Alberto Gómez Roda}

dentro de organizaciones de masas. En absoluto faltaba la violencia ni la exclusión, pero con arreglo a la divisoria que aparece en el título de una conocida obra de Detlev Peukert: "camaradas nacionales" (Volksgenossen) y "extraños a la comunidad nacional" (Gemeinschaftsfremde) (nota 4). La distinción sería sólo retórica y propagandística de no haber sido llevada adelante hasta sus últimas consecuencias. Frente al juego de la movilización plebiscitaria y la exclusión de minorías diversas ajenas a la nación ideal, superadora de divisiones políticas y de clase, el franquismo se consolidó sobre seguridades más efectivas y estables: represión militar para enemigos políticos y perturbadores del orden público, permisividad en los negocios, una inédita explotación de las clases trabajadoras, liturgia y escuela nacional-católica para el adoctrinamiento de las nuevas generaciones.

El "descubrimiento" de los sujetos bajo el yugo fascista ha abierto a la historiografía el análisis de sus percepciones. Así se ha terminado con la idea de un adoctrinamiento ilimitado de masas a la que nos tenía acostumbrados la teoría del totalitarismo. En España, los historiadores han adoptado estas nuevas perspectivas y evalúan el significado de los comportamientos transgresores, se pronuncian sobre la despolitización de las percepciones y la politización del trato que reci- 
Percepciones de las instituciones y actitudes políticas de la sociedad en la posguerra

bían los ciudadanos por parte de las instituciones, analizan las amplias "zonas intermedias" o grises, se preguntan si hubo alternativa integradora a la represión y buscan identificar el núcleo o base de consenso del régimen.

\section{Los documentación de las percepciones de las institu- ciones de posguerra en Valencia}

En lo que sigue nos apoyamos en una investigación colectiva que dio sus primeros pasos en 1996 a partir de un trabajo de documentación realizado en dos direcciones: la recopilación de fuentes escritas de diversa procedencia que informasen sobre las actitudes políticas de los valencianos en los años 40, y la producción de documentos de historia oral en cinco ámbitos sociales acotados: los obreros de dos grandes factorías (los astilleros de "Unión Naval de Levante" en Valencia y la siderurgia de "Altos Hornos de Vizcaya" en el Puerto de Sagunto), clases medias del tejido social católico y festivo fallero de la ciudad de Valencia, y trabajadores de un pueblo agrario, Llíria. Los documentos que utilizamos proceden del Public Record Office británico (PRO), de Falange (FET-JONS), del Partido Comunista de España (PCE), del Negociado de Orden Público del Gobierno Civil de Valencia (OP-GCV), y del fondo de documentos orales creado para el 


\section{J. Alberto Gómez Roda}

proyecto. Respecto a la cronología, destaca la concentración documental en los años 1943-1944 con la excepción de los informes del Partido Comunista de España, que comprenden los años 1946-1955 (nota 5).

En los años 80 , la historia oral alcanzó una notable popularidad. Como arma de la nueva historiografía radical para dar voz a la gente común "sin historia" se llegó a argumentar su superioridad a la fuente escrita en este terreno. Con el tiempo, los debates sobre la subjetividad, representatividad y fiabilidad de la fuente oral han permitido valorar de forma más ponderada sus virtudes y desventajas. Para conocer la percepción de las instituciones por la gente corriente, la fuente oral es uno de los instrumentos más pertinentes que se nos ofrecen. Tiene la ventaja de recoger la cotidianidad despolitizada en que se producían la mayoría de las percepciones frente a la politización habitual en los documentos escritos y en la historiografía digamos "tradicional". También el documento oral es interesante porque la integridad de la reconstrucción biográfica individual permite observar la simultaneidad de comportamientos del pasado que, a nuestra mirada, parecen contradictorios entre sí, aunque respondan a la lógica subjetiva del testimonio. Pero aquí radica el principal problema del documento oral para el objetivo que nos pro- 
Percepciones de las instituciones y actitudes políticas de la sociedad en la posguerra

ponemos, el de la memoria desde el presente y sus mecanismos censores y de cambio en la atribución de sentidos y significados.

En este artículo, hemos tomado la opción de realizar una reconstrucción fundamentalmente con informes del archivo histórico del PCE. El autor de estas líneas no tuvo participación en la creación de documentos orales y, sin embargo, en su análisis y evaluación pudo constatarse que una parte importante de los lugares comunes de la memoria del franquismo recuperada en 1997-98 se hallaban ya recogidos en los informes comunistas de 1946-55 junto con otros aspectos olvidados. Es cierto que la consulta de esta documentación ha hecho concentrar nuestra atención en segmentos de la población potencialmente más proclive a la izquierda derrotada en 1939 como eran las clases trabajadoras, sin que hallan quedado al margen otros sectores de gran peso social en el País Valenciano, como eran los pequeños comerciantes e industriales. Escasamente atendidas han quedado las percepciones de los sectores que constituían la base de consenso del régimen, en absoluto inexistente, así como las percepciones de género. El campo de investigación es amplio y puede encontrarse un creciente número de trabajos sobre el 


\section{J. Alberto Gómez Roda}

mismo que completan, profundizan y corrigen nuestros conocimientos.

\section{Represión y control social}

El 29 de marzo de 1939, el Ejército de Galicia al mando de Aranda ocupó Sagunto, y el de Castilla encabezado por Varela llegó a Segorbe. Al día siguiente eran ocupadas militarmente Valencia y Alicante. Una serie de imágenes de los militares y grupos paramilitares nacionalistas refieren su percepción como fuerzas de ocupación: violencia arbitraria e impune, actos criminales de las temibles tropas marroquíes del ejército de África, y requisas incontroladas (nota 6). Podemos añadir la imagen de los reclutas que abandonaban sus unidades al desintegrarse el ejército republicano, apresuraban la vuelta a sus lugares de origen y se encontraban los controles improvisados en las carreteras por "quintacolumnistas" y falangistas. Para éstos, la inmediata llegada del ejército de Franco era la seguridad que necesitaban para poner fin en muchos casos a una experiencia de camuflaje y ocultación durante la guerra.

El ejército de los años de la II Guerra Mundial se percibe como una fuerza desproporcionada hasta la normalización de la recluta para el servicio militar y el fin de la guerrilla, con 
Percepciones de las instituciones y actitudes políticas de la sociedad en la posguerra

una alta presencia de hijos de las clases populares del derrotado bando republicano, míseros y mal tratados. El temor a un ejército de "rojos" era uno más de los argumentos que esgrimía la opinión conservadora contraria una nueva guerra en la que España luchase al lado de Alemania: "it would be unsafe to give rifles and machine guns to the thousands of men still imbued with communistic ideas". Jóvenes comunistas "camuflados" en el ejército vencedor fueron Manuel Tuñón y Julio Marco. Para ellos, convertirse en "soldados de Franco" fue una salvación buscada para evitar el batallón de trabajadores, en el caso de Tuñón, enrolándose voluntario "por falta de medios para subsistir" en el de Marco (nota 7). Tras evitar la prisión y el batallón de trabajadores, veían al ejército como "una cárcel más". Evitaban comunicarse entre ellos en un sentido político, menos aún organizarse. Percibían que la inmensa mayoría de los reclutas eran de origen popular, dominados por el terror y controlados por las denuncias y avales de los pueblos, "entregados a un servicio de disciplina que les convierte en verdaderas bestias, mal alimentadas, permanecen durante tres años por lo menos, cuando no de cinco a seis" (nota 8). En el caso de los soldados de las quintas más jóvenes, apenas habían tenido tiempo de formar su identidad política durante la guerra (nota 9). Esta no fue una oportunidad aprovechada por el "Nuevo 


\section{J. Alberto Gómez Roda}

Estado" para integrar y "homologar" a los reclutas procedentes de zona roja con los nacionales. En lugar de ello, los reclutas valencianos eran señalados como rojos, lo que era percibido con desagrado y temor, de donde hemos de interpretar con Ismael Saz que fueron "rojos por castigo y por obligación" (nota 10).

La efectividad paralizadora de la acción represiva se pone de manifiesto en la percepción de la justicia de Franco como máquina tan implacable como arbitraria y en el recuerdo de una abrumadora presencia de fuerzas de orden. Para Ángel Gaos, que se vio entre rejas hasta 1946 después de haber tenido menos responsabilidad política que dirigentes comunistas que habían salido ya en libertad en 1943, era "una lotería". Observaba en Valencia un "gran lujo de Policía Armada", además de "Policía secreta y grupos de Falange que aunque no oficiales gozan de impunidad", aunque "el terror había remitido muchísimo" y no sabía de ejecuciones desde hacía dos años (nota 11). La represión por las fuerzas regulares tuvo colaboradores, fuesen coaccionados, voluntarios o instigadores (nota 12). Su actuación dejó una huella indeleble en forma de temor a delatores y grupos falangistas cuya actividad parapolicial era tolerada si no alentada desde el poder cuando las víctimas eran rojos. El caso extremo lo 
Percepciones de las instituciones y actitudes políticas de la sociedad en la posguerra

encontramos en el interior rural, donde sembraron el terror entre los masoveros las "contrapartidas" de la guardia civil a las que temían más que al instituto armado. Más común era el miedo a la agresión anónima por motivos menores. Es relativamente frecuente el testimonio de haber sido golpeado, arrestado o multado inesperadamente por blasfemar, no alzar el brazo al paso de la bandera nacional o trabajar en domingo (nota 13).

Los expedientes de orden público revelan "desde abajo" las exigencias sobre el aparato represivo y su instrumentación para fines particulares, haciendo en ocasiones uso de la presunción de criminalidad que llevaba aparejado el estigma de rojo. Nos informan también del lenguaje y las expectativas de núcleos derechistas víctimas a su vez de la feroz violencia de izquierdas durante la guerra civil. Conocemos un caso interesante, sin que pueda tomarse como generalizable y sin saber si sus aspiraciones tuvieron éxito. El 13 de mayo de 1943, los familiares de "caídos" de un pueblo de la Canal de Navarrès manifestaban su repulsa por la vuelta al mismo "de la casi totalidad de los elementos delincuentes" beneficiados por un decreto del 1 de Abril de 1941: "Sujetos que intervinieron directamente en la detención de nuestros familiares, para ser más tarde asesinados; elementos que saquearon 


\section{J. Alberto Gómez Roda}

nuestros domicilios, se incautaron de nuestras propiedades, incendiaron y profanaron los edificios religiosos y las imágenes representativas de Nuestra Sacrosanta Religión. Asesores del comité rojo local, sicarios a las órdenes del mismo, que persiguieron con ensañamiento criminal toda persona u cosa que representase el orden. Espías, delatores y toda la gama de que estaba compuesta la tiranía local...". El decreto en cuestión concedía la libertad condicional a los presos con penas no superiores a los doce años. Solicitaban la aplicación del artículo $2^{\circ}$ del Decreto que establecía el destierro durante el tiempo que les restase de la mitad de la condena (nota 14).

Policías, guardias civiles y oficiales del ejército eran vistos como "privilegiados" por el resto hambriento de la población: tenían racionamiento asegurado y hacían estraperlo (nota 15). De una forma más matizada, Tuñón pensaba que los militares de alto rango eran fieles a Franco "porque con pagas, gratificaciones, dietas, suministros, automóviles, etc., son el grupo privilegiado del país" y por complicidad desde su intervención en la represión. En los cuadros medios habría "más descontentos e indiferentes, pero siempre son una minoría". Los cuadros inferiores de la oficialidad, "de capitán para abajo", eran los "formados por el franquismo y elevados 
Percepciones de las instituciones y actitudes políticas de la sociedad en la posguerra

a base de la guerra", de donde deducía que era el segmento de una fidelidad más incodicional al generalísimo. Tuñón entendía que sólo en la oficialidad de complemento formada en las "Milicias Universitarias" podía esperarse tal vez la infiltración de elementos antifranquistas. Francisco Olmos, del PSUC, informaba en junio de 1947 de los descontentos por debajo de la oficialidad en el seno de las fuerzas de orden. Por debajo de la alta oficialidad, el malestar y dificultades de militares y policías por los bajos salarios debía manifestarse a la vista pública de "muchos oficiales que fuera de las horas de servicio trabajan en casas comerciales, de contables, o son comisionistas...", según un informe de 1949 (nota 16). Según otro de 1952, los miembros de la Policía Armada no ganaban para vivir y se hacían representantes, cobradores de comercio, y pequeños estraperlistas: "van al puerto y entran en los barcos y compran y luego lo llevan a vender a una tiendecita que hay allí que a la dueña le mataron al marido en guerra" (nota 17).

\section{Política y administración}

Los informes comunistas de 1946 perciben una Falange omnipresente en la vida política y social de los españoles. En la percepción comunista de las instituciones, "excautivos, ex- 


\section{J. Alberto Gómez Roda}

combatientes, etc., controlados en las organizaciones falangistas, ocuparon, no solamente los lugares de dirección (...) sino los mejores y hasta modestos puestos en el trabajo." Las clases medias, nervio de la experiencia republicana y ahora depauperadas y proletarizadas, habrían visto "pospuesta y relegada su misión societaria por esa especie de aristocracia franquista que ha invadido y monopolizado la sociedad". Entre todas las instituciones de la dictadura, la Falange era la organización contra la que se dirigían todos los odios y críticas en los primeros años del régimen. Se manifiesta de forma casi unánime y con la mayor crudeza en fuentes de todas las procedencias políticas. Entre todas las críticas queremos destacar por su relevancia la de Carrero Blanco en su primer informe sobre la situación interior de España de agosto de 1941 tras ser nombrado Subsecretario de la Presidencia: "En la zona nacional todo el mundo fue falangista, y es evidente que lo mismo que en la roja, gentes que no eran rojas encontraron su seguridad en la UGT o en la CNT, en la nacional gran masa de rojoides, o rojos sin paliativos pero de personalidad poco destacada, de masones, de amorales y simplemente de vividores, encontraron en la camisa azul y en sus más estentóreas manifestaciones externas (mucho grito, mucho viva y mucho saludo nacionalsindicalista) una seguridad y un medio para situarse." Y aña- 
Percepciones de las instituciones y actitudes políticas de la sociedad en la posguerra

día que "los osados, los logreros, que suelen ser listos y hábiles se filtraron indudablemente en la jerarquía, y su acción pesó en la acción del conjunto, influyendo sin duda en que se tomara un derrotero equivocado, que ha conducido a una situación que hoy requiere una seria rectificación" (nota 18). En este mismo informe, Carrero se pronunciaba por un partido cuya fuerza no estuviese en la masa "cuando ésta no tiene más base de homogeneidad que un uniforme y un carnet", sino en una minoría selecta que ejerciese el gobierno con una adhesión inquebrantable a Franco. La impresión sobre Falange recogida en medios conservadores ya en 1939 por el cónsul británico en Valencia no era muy diferente: "many nationalists dislike the Falange as being the happy hunting ground for rascals and irresponsible youth" (nota 19). Según el embajador Hoare los oficiales del ejército, como también la Iglesia, detestaban "the weedy, inexperienced and uneducated young men in blue shirts, who wangle black-coated jobs and, by their incompetence, ruin the machine of government". Los españoles identificaban el falangismo con la política y los métodos alemanes, y añadía: "To the Spaniard, the New Order has meant old anarchy, chaos and corruption worse that any in the previous chapters of his history. It has riveted upon his neck starvation, terrorismo and incompetence. It has filled the administration and its surroundings with 


\section{J. Alberto Gómez Roda}

cruel and contemptible gunmen and informers" (nota 20). Años después, en 1946, con el ex-divisionario Ramón Laporta al frente del Gobierno Civil de Valencia, el comunista Ángel Gaos afirmaba sin dudarlo que Falange era "el partido más impopular que ha existido nunca en España" (nota 21). Según él, a la creciente presencia institucional de los hombres de Acción Católica tras el cambio de gobierno de 1945 los falangistas habrían respondido presentándose unida a Franco con un discurso de "oposición desde el poder" contra los capitalistas para ganarse el apoyo de los trabajadores. En su opinión, compartida por varios otros informantes comunistas como luego veremos, la política falangista de "concesiones demagógicas" no tendría éxito entre los obreros pero pondría "en trance de ruina a muchas empresas" y provocaría al mismo tiempo el "recelo y animosidad en ciertos círculos económicos".

En agosto de 1941, el jefe provincial de FET-JONS de Valencia exculpaba al partido por "todos los errores y desmanes de las Autoridades que están enfrente de nosotros" (nota 22). En el otoño de 1939, la Falange de Valencia había realizado una campaña contra alcaldes de la provincia no afectos al partido, con denuncias por inmoralidad y estraperlo, pasado político dudoso o protección de izquierdistas, las 
Percepciones de las instituciones y actitudes políticas de la sociedad en la posguerra

mismas que encontramos en el origen de diversos expedientes de Orden Público. A ello se unió la labor de fiscalización por las jefaturas locales que a su vez eran vigiladas por la Inspección Provincial. Las denuncias falangistas adoptaban el lenguaje de la intransigencia fascista contra la "vieja política" caciquil que había renacido por doquier. Joan Adrià en su investigación sobre Llíria ha destacado el tráfico de avales que alimentaba relaciones locales de patronazgo y clientelismo superpuestas a la gestión administrativa regular. Entre junio de 1943 y enero de 1944 realizó el gobernador falangista Ramón Laporta la unión personal de las funciones de alcalde y jefe local de FET-JONS en la provincia. Salieron a su encuentro multitud de denuncias que se rechazaron por falsedad, evitando que contribuyesen a prolongar la inestabilidad a la que se quería poner término, provocada por el recurso sistemático a la denuncia política institucionalizado en la Delegación de Información e Investigación del partido y que podía volverse en su contra. No es extraño que en enero de 1945 el Inspector Provincial de FET-JONS de Valencia, Ángel Ortuño, afirmara en una conferencia ante los nuevos alcaldes de los pueblos de la provincia que "a más de las denuncias, el enemigo político número uno es el bulo" (nota 23). 


\section{Consumo y producción}

El motivo principal de descrédito del nuevo (des)orden era el malestar popular causado por el hambre. En los primeros años la opinión popular no se resignaba y los informes británicos muestran que se atribuía el hambre tanto al expolio exterior como al caos sembrado por la incompetencia y la corrupción institucional. La economía intervenida y la carestía eran el motivo de la más sonora y extensa expresión de descontento, por contraste con el también amplísimo silencio político. En 1946 González Bastante refería múltiples actos aislados de protesta, todos motivados por la carestía y los bajos salarios, pero se pronunciaba contra la exageración sobre su extensión y alcance, también contra una interpretación política de los mismos. Efectivamente, rumores, bulos y críticas desprenden una radical ambigüedad respecto al régimen. A la altura de 1949, el sentido político de la protesta se habría al menos sumergido completamente: "no se habla nominalmente contra Franco y Falange, pero se habla públicamente contra todos los hechos concretos que son el reflejo de la política franquista: la comida, las restricciones, etc. etc" (nota 24). 
Percepciones de las instituciones y actitudes políticas de la sociedad en la posguerra

\section{Hambre, supervivencia y racionamiento}

La ambigüedad política más evidente la encontraríamos en los rumores que, por definición, circulaban favorecidos por el anonimado. Así surge con insistencia el de la salida masiva de alimentos de España hacia Alemania por compromisos adquiridos por Franco, y la vinculación de entidades como la Rama de la Naranja a la presencia siniestra de agentes extranjeros. Los propios informes británicos identificaban la economía autárquica con la Falange y la influencia de los intereses nazis: "Spain lies bleeding with the claws of Italy and Germany firmly embedded in her flesh, Germany being far the greater danger" (nota 25). En 1946 la idea del expolio mostraba su ubicuidad al apuntar en otra dirección: "El grueso de la cosecha va al extranjero, principalmente a Inglaterra, país que, a través de una llamada 'Junta de Compras' controla toda la producción nacional como antes la controlaba Alemania". Obviamente, además de situar en el exterior el origen del hambre en España, el sentido político de esta persistente idea podía ser nacionalista, aunque de signo republicano o franquista indistintamente.

La vida y las percepciones cotidianas de la gente común aparecen reducidas al horizonte pragmático y más inmediato de sus necesidades. Las estrategias de supervivencia mo- 
vidas por el hambre no excluían ninguna dependencia y sí desaparecía, por necesidad, cualquier resquicio de resistencia ideológica. En las cárceles, las ejecuciones y los maltratos brutales, las condiciones de vida atroces, el hambre y las muertes por avitaminosis ponían a prueba la resistencia ideológica de los militantes presos a perseguir el favor de los carceleros. Los presos de El Dueso, asediados por el hambre y aterrorizados por la visión diaria de cadáveres hinchados de compañeros muertos, practicaban el mercado negro entre sí y "se agarraban a la influencia de las monjas (buscaban una ración de enfermería)". Sólo el hambre justificaba para el informante comunista lo que desde su punto de vista podía considerarse una muestra de debilidad ideológica (nota 26).

Las cárceles nos sitúan ante la situación extrema de lo que, en otra medida, era la lucha de la gente común por sobrevivir. Un caso entre tantos lo encontramos en el informe de septiembre de 1949 sobre Elisa Carrio, compañera de un dirigente comunista exiliado. Al preguntarle sobre la "situación de las masas", ponía por ejemplo su propia familia: "No sólo comen mal, sino que se entrampan. Con frecuencia para terminar el mes, tienen que echar mano del dinero del Colegio de Abogados que maneja el padre (es cobrador) y apresu- 
Percepciones de las instituciones y actitudes políticas de la sociedad en la posguerra

rarse a cobrar para reponerlo y que no se descubra. A veces la madre se veía obligada a recurrir a una prestamista recibiendo dinero al 10\% mensual". Elisa tenía 34 años y era mecanógrafa en el Colegio de Abogados, empleo que había conseguido por un amigo, abogado de ideas tradicionalistas "bien situado". Resulta significativo que, en su vida cotidiana, Elisa no percibiese en muchos abogados derechistas del Colegio a los enemigos políticos causantes, en la opinión del PCE, de la miseria en que vivía. Ante la sorpresa y la desconfianza de su interrogador comunista, a buena parte de estos "franquistas" los juzgaba como "buenas personas". ¿Cómo, sabiendo quién era su marido, no le pusieron inconvenientes al ser contratada por el Colegio, "cuando los fascistas se cebaban sobre los comunistas y el pueblo"? Para una mente militante, la respuesta de Elisa era desconcertante: "No se interesaban por mí. Yo era para ellos un número como en el cuartel". Las sospechas del interrogador aumentaron ante "tanta generosidad", de la que se habían beneficiado también "su hermano, sargento de la guerra, pasado a Francia en 1939 y que a su regreso ni fue encarcelado ni procesado. Explicación: "Unos amigos le consiguieron avales". Su padre, Comandante de nuestro Ejército, voluntario, en 1940 sale ya a la calle y no fue condenado más que a 6 años (...). Explicación: "Quizás se deba a que es un hom- 


\section{J. Alberto Gómez Roda}

bre católico." Elisa no era capaz de señalar a ningún "bandido fascista" y su explicación era que odiaba "a Franco y poco menos que a un enemigo invisible". Todo esto lo decía con una "naturalidad" que no daba "la impresión de frivolidad, sino de simplicidad".

Otra evidencia de la "inmediatez" de las percepciones la encontramos en la reacción de la población consumidora al fin del racionamiento en 1952: "cuando se habla de bajas, se comparan con los precios actuales, no con los de los artículos racionados, sino con los precios de estraperlo" (nota 27). La desaparición de lo que en los libros de historia es un signo de la larga posguerra y de la tardía recuperación de la economía hizo daño a muchas economías domésticas que habían integrado el recurso al racionamiento con la práctica del estraperlo: "Con esta medida han conseguido restringir mucho la venta de pan de estraperlo, con lo que muchas familias han perdido un medio de ingresos que no lo pueden sustituir con el trabajo, y reducir las ganancias de los panaderos, para ganar más el Servicio Nacional del Trigo. Esta medida no ha entusiasmado a nadie". Los jóvenes de 1955 , que no podían recordar una situación de "normalidad" en la subsistencia cotidiana, no veían agresión o castigo político alguno en la necesidad que había existido del recurso al es- 
Percepciones de las instituciones y actitudes políticas de la sociedad en la posguerra

traperlo. Les parecía "natural" y lo incluían entre otras muchas vivencias de su infancia y adolescencia: "Es natural que vayas en el tranvía y te quedes media hora parado sin electricidad, siempre ocurrió así. Es natural que exista el voltímetro en la radio por las alzas y bajas de la corriente. Es natural la estafa y el estraperlo porque su propia madre tuvo que hacerlo para comer. Es natural que el cine sea más caro el domingo..." (nota 28 ).

\section{El origen de los alimentos racionados: la provincia agraria}

Muy distinta era la percepción del estraperlo en lo que podríamos denominar provincia agraria, donde la posesión de alimentos como productor marcaba la diferencia. Había multas, decomisos, clausuras, y otras sanciones. Un informe comunista de 1946 sostenía que los campesinos estaban "en lucha constante con las organizaciones de abastos" (nota 29). Parece un tanto exagerado, aunque algo de ello debía haber cuando en los expedientes de orden público encontramos casos como el de Utiel, donde la alcaldía solicitaba en julio de 1943 el auxilio de la guardia civil para vencer la rebeldía de los propietarios a la "recogida del cupo de trigo asignada a esta población", que obligaba a vigilar la trilla 


\section{J. Alberto Gómez Roda}

en las varias eras de la población a fin de evitar el fraude y lograr la entrega de la parte proporcional correspondiente (nota 30). En cambio, otro informante comunista se negaba a aceptar "como víctimas del fascismo a los pequeños poseedores de tierra" por las oportunidades de beneficio que ofrecían los altos precios del mercado negro a cultivadores excedentarios.

En el campo, una institución nueva que trajo el franquismo fue la Hermandad de Labradores. Una de sus actividades era el reparto de cupos de abonos y fertilizantes entre los agricultores de los pueblos: "Estas se encuentran en los mismos locales que la CNS; se encargan de la repartición de los cupos de abonos, y en general del reparto de todos los productos de importación y también de la policía rural; da la sensación de ser una especie de Secretaría u organismo de control". En este caso la intervención permitía un tráfico entre el cupo a precio de tasa y el mercado libre en beneficio de los grandes terratenientes (nota 31). Este era un negocio "legal", entre otros que permitía la existencia reconocida institucionalmente de dos mercados y la tolerancia del tráfico lucrativo de mercancías de uno al otro. 
Percepciones de las instituciones y actitudes políticas de la sociedad en la posguerra

\section{Los cupos industriales: "monopolistas" y excluidos}

La burguesía sería para el comunista González Bastante una clase social decepcionada con Falange por la catastrófica situación económica, y no por motivos políticos ni por nostalgia de la monarquía. No sólo causarían su descontento las restricciones eléctricas, la "distribución ilusoria" de materias primas que obligaba a adquirirlas a precios altísimos en el mercado negro o el desgaste de la maquinaria, inutilizada y reducida al $50 \%$ de su capacidad. A ello había que añadir "los enormes impuestos que la industria y el comercio han de tributar al Estado, a través no sólo de Hacienda sino de centenares de nuevas instituciones." La represión y el orden impuesto por medios militares y policiales sería la compensación para una burguesía contraria a la intervención autárquica con todo su aparato institucional: "El ideal de esta burguesía sería un régimen falangista sin Fiscalía de Tasas, sin Comisaría de Abastecimientos y Transportes, sin Consejo Ordenador de la Industria, sin Distribuidora Nacional; un régimen falangista con libertad de importación y exportación, de adquisición de materias primas y precios, un régimen falangista donde Franco, al que no sólo acatan, sino que respetan e incluso quieren, continúe velando por los intereses de sus industrias y comercios" (nota 32). 
En general, al igual que en la agricultura, en la industria se percibía una divisoria clara que venía dada por la exclusión de los "vasos comunicantes" entre las instituciones y el mercado ilícito. Era una percepción muy extendida que el estraperlo tenía "su salida de origen en las mismas fuentes de producción, en los grandes almacenes de la Comisaría de Abastecimientos y Transportes, organismo estatal. El estraperlo oficial del tabaco o los neumáticos, por ejemplo, es escandaloso. (...) El estraperlo de los neumáticos lo hace la misma Policía Armada y de Tráfico, que, en Valencia, tiene su base de operaciones en un bar llamado 'City', frente a la Plaza de Toros. De los centros de almacenamiento oficial, los mismos empleados lo venden a 'comisionistas' y asentadores, los cuales los distribuyen entre los revendedores, una verdadera masa de estraperlistas que invade toda la ciudad" (nota 33). Un lugar común en los informes comunistas de finales de los 40 era la concentración, y por tanto, la exclusión, que parecía observarse en los negocios de estraperlo. En junio de 1947, Francisco Olmos, militante del PSUC, percibía una notable disminución del número de estraperlistas que parecía anunciar la desaparición del mercado negro. Advertía que se trataría de su concentración en pocas manos, que gozaban de "todas las prerrogativas y de fuertes capitales", y refería negocios fraudulentos y sospechosos de 
Percepciones de las instituciones y actitudes políticas de la sociedad en la posguerra

ministros, sindicatos, gobernadores y delegados de abastos, alcaldes, militares e incluso el clero. Percibía en correspondencia un cambio de actitud de la pequeña burguesía, que ya no podría practicar el estraperlo para resarcirse de impuestos e intervenciones sin dejar de sufrir "las multas más - menos arbitrarías de Fiscalía de Tasas y Hacienda". Pequeños comerciantes e industriales habrían venido así a "aumentar el número de descontentos", aunque no el de los antifranquistas por temor "a las consecuencias de una revuelta revolucionaria al estilo FAl". En este terreno político, las cosas habrían cambiado poco desde el final la guerra civil.

Así, "vendidos" por sus propias prácticas, muchos derechistas discriminados por la brecha abierta entre estar o no en los centros de regulación y distribución, cuando querían, no podían defenderse contra la corrupción porque las "autoridades" eran juez y parte. Interpretamos que esta podría ser la percepción implícita en el relato de una asamblea de la patronal de hosteleros, dueños de bares y cafés en 1949 donde se cuenta que los pequeños patronos criticaron a los "jerarcas patronales de este Sindicato" por acaparar el cupo de azúcar y por fraude en la administración de los llamados "impuestos concertados". Se encargó a una comisión "revisar 
todas las denuncias, comisión en la que están sin embargo los propios acusados y amigos suyos" (nota 34).

\section{Multas, requisas... impuestos}

De la posguerra nos llegan percepciones de la obligación tributaria con el Estado distorsionadas por el sentido punitivo y a menudo arbitrario de muchas imposiciones directas creadas ad hoc para el sostenimiento de los recaudadores. Como ejemplo, en un informe de 1946 leemos: "Los impuestos a que está sometido el mercado son múltiples. De un lado el Ministerio de Hacienda con sus contribuciones elevada al cubo; por otro los múltiples organismos creados por Franco, tales como el subsidio al Combatiente, el Impuesto de Lujo -sobre usos y consumos-, el Subsidio Familiar; y centenares de contribuciones 'voluntarias', a las que todo el mundo está obligado a tributar. Las multas son el medio más eficaz, para obtener recursos, empleado por el Gobierno franquista. Existe un organismo, la Fiscalía de Tasas, por medio del cual, cada vez que el Gobierno o Falange necesitan dinero, logran lo que se necesita (...). Las multas se le imponen a cualquiera; Falange y la Fiscalía de Tasas, saben que todo el mundo hace straperlo (sic) y, si no lo hace, basta con que tengan el dinero para descargar el golpe" (nota 35). En otro informe de 
Percepciones de las instituciones y actitudes políticas de la sociedad en la posguerra

1949 se refería al aumento desorbitado de impuestos en los términos siguientes: "Las contribuciones han aumentado mucho. Hoy pagan los industriales un 98 '32\% de recargo sobre sus propias contribuciones para el tesoro. Hace un año pagaban un 78 '32\% de recargo. Este aumento de $20 \%$ se llama "transitorio" (nota 36). Esta situación es constatable en casos como el del puerto de Valencia, donde una investigación abierta para conocer las causas de un excesivo coste de los fletes halló una irracional superposición de tasas en cada trámite de paso de la carga.

A finales de los años 40 , según hemos visto, la pequeña industria y el comercio atribuían a estos impuestos y multas "vampirizadores", y al raquítico consumo popular, las dificultades por las que atravesaban. Al respecto, en 1955 un contable comunista informaba sobre las prácticas y actitudes de los propietarios de dos fábricas donde trabajaba, una de guantes y otra de pastas para sopa. Al fabricante de guantes lo presentaba como un arribista explotador que "entró en la fábrica de meritorio y se hizo con la fábrica robando". Para evitar pagar impuestos llevaba dos contabilidades. El otro industrial sólo alcanzaría en beneficios "lo justo para vivir". Ello sería debido a "los impuestos, la subida de jornales y las condiciones que le imponen para el embalaje". Tenía que 


\section{J. Alberto Gómez Roda}

pagar timbre por los paquetes de envasado, otro impuesto al ayuntamiento concertado con los demás fabricantes del gremio, y un llamado "impuesto de las precintas-control" a su Sindicato. Las dificultades de estas dos pequeñas industrias y otra de calzados de goma radicaban en la estrechez del mercado. Así, el de pastas de sopa sufría la competencia de los clandestinos, "campesinos en su mayoría que tienen una pequeña máquina, de poca cosa, y que durante un par de meses revientan el mercado sobre la base de harina de estraperlo de los molinos" (nota 37). Reforzando la misma idea encontramos con frecuencia en los informes la referencia a quiebras y cierres de empresas.

\section{Trabajo y condiciones laborales}

“... éste es de los que reclaman”. La imposibilidad del despido libre, las C.N.S. y las reclamaciones en Magistratura

Un informe comunista de 1946, que atribuye a los sindicatos verticales las mismas funciones que tenían los jurados mixtos de la República, la afiliación obligatoria a la CNS era percibida con hostilidad como una carga más por los obreros, mientras que los empresarios la aceptaban por conveniencia y precaución (nota 38). En un documento de 1949 leemos 
Percepciones de las instituciones y actitudes políticas de la sociedad en la posguerra

otro de los lugares comunes de los informes de aquella época: 'Los 'Sindicatos Verticales', con una política demagógica, han conseguido atraerse, en parte, la consideración de masas obreras. Para ello, emplean como principal arma la prohibición a los patronos de expulsar al obrero del trabajo; por esta misma razón -dice- los patronos, que 'se ven lesionados en sus intereses' reaccionan mostrando su disconformidad con esta medida que consideran arbitraria, ya que no pueden mantener el ritmo de producción que el franquismo les impone" (nota 39). En mayo de 1949, un viejo comunista, inactivo desde su salida de la cárcel en 1943, sorprendía a sus interrogadores con afirmaciones desconcertantes que apuntaban en la misma dirección:

"Hay muchas quiebras y suspensiones de pagos, muchos pequeños comercios e industrias cierran. Según el informante, los despidos no representan actualmente una gran tragedia, pues como los patronos no pueden despedir de acuerdo con las leyes a sus obreros sin más ni más, se ven obligados a indemnizarles con un mes de salario por cada año trabajado lo que a algunos les reparten una cantidad nada despreciable. La tragedia será después cuando se hayan comido la indemnización. No ha notado una reacción combativa de parte de los obreros contra los despidos. Los parados se 


\section{J. Alberto Gómez Roda}

dedican a vender macarrones, a intermediarios y a hacer estraperlo. En cuanto a los obreros que trabajan cree que se acogen a la legislación social, por cuanto los 'sindicatos verticales tienden a apoyar a los obreros en sus diferencias con los patronos.' Estos se refiere a la pequeña industria por cuanto luego dice que en cambio, cuando se trata de los grandes patronos, los sindicatos están de su lado. Esto último lo dice con mucha convicción. No puede decir qué piensa la clase obrera porque no ha convivido con ella ni ha hecho vida activa de partido. No obstante cree que no hay una perspectiva política."

El redactor del informe obtuvo de esta entrevista la "impresión de un desconocimiento y desinterés enorme de las masas por los problemas políticos" (nota 40). La percepción de Elisa Carrio sobre la indemnización que por despido podía ordenar la Magistratura de Trabajo insiste más en la resignación e indefensión de los obreros, sin las evidentes distorsiones del anterior: "El régimen hace muchos esfuerzos por dar la sensación de que ayuda a los obreros, puntos, subsidios, salario de los domingos, etc. 'Pero esto que no alivia la situación de los obreros, arruina a los patronos'. Es frecuente que los trabajadores reclamen en los sindicatos y lleven sus reclamaciones a la Magistratura, pero bien porque no se 
Percepciones de las instituciones y actitudes políticas de la sociedad en la posguerra

les atienda, bien porque es muy lento se dan por vencidos. Así los obreros lanzados al paro, aceptan una indemnización" (nota 41).

Lo visto hasta aquí y los testimonios de los trabajadores demuestra que un caso aparte en materia de protección laboral sería el de grandes factorías como la Unión Naval de Levante en el Grao de Valencia o los Altos Hornos de Vizcaya en el Puerto de Sagunto. Aquí los trabajadores chocarían con la abstención de las autoridades laborales a intervenir. Estas empresas tenían su propio y efectivo régimen de disciplina y beneficios para sus trabajadores.

\section{“... ir a Madrid a hablar con el ministro". Paternalismo y 'gironismo' en el área industrial portuaria de Valencia}

El área portuaria de Valencia fue la zona industrial por excelencia de la ciudad del Turia hasta los años 60. Era también una zona conflictiva de hegemonía cenetista hasta la guerra civil, el escenario destinado a protagonizar protestas como las de la Ría de Bilbao de 1947 o la de Barcelona de 1951. Pero Valencia no ocupa lugar destacado en la conflictividad laboral contra la dictadura hasta 1974. Una correcta explicación de este bajo perfil conflictivo obligaría a incluir diversas variables que pudieron ser determinantes, unas más objeti- 


\section{J. Alberto Gómez Roda}

vas o "estructurales" y otras más "subjetivas". Entre estas últimas se debe contar el análisis de la acogida obrera al paternalismo industrial y la "demagogia gironista" de posguerra, de su alcance y sus límites (nota 42).

Algunos lugares comunes de los informes comunistas, como la desprotección de los obreros de grandes empresas en sus reclamaciones, los encontramos en los relatos de obreros de los astilleros de la empresa "Unión Naval de Levante" en las entrevistas realizadas entre 1997 y 1998. Pero éstos añaden el aprecio por el cuidado de la empresa con sus trabajadores: racionamiento y economato, la "Benéfica", viviendas, escuela de aprendices, y otros beneficios del paternalismo industrial. En el mismo conjunto de lugares comunes, en versiones épicas de protesta obrera, acciones exageradas en los informes comunistas, o de difícil valoración aisladas de otras muchas de su contexto, surge como tópico la expresión "ir a hablar con el ministro". Incluso algún testimonio oral afirma haber mantenido correspondencia con José Antonio Girón. En el sector químico, del que se refiere un estado de conflicto latente en 1952 y al que pertenecía la única empresa que en los años 50 rompió entre sus muros la "paz laboral" reinante, encontramos esta misma apelación directa a Girón. En la factoría de la "Papelera Española", con unos 
Percepciones de las instituciones y actitudes políticas de la sociedad en la posguerra

1100 trabajadores, los enlaces sindicales habrían recibido el encargo de la CNS de elaborar unas "nuevas bases de trabajo para presentarlas al Ministro" Girón, quien consideró que pedían poco al solicitar un salario mínimo de 31 pesetas. Insistieron en obtener esta concesión antes de ampliar sus aspiraciones. Les fue denegada y amenazaron con dimitir, por lo que se les convocó a una reunión con el Gobernador en la que éste les amedrentó (nota 43). Sucesos de parecida índole habrían tenido lugar por las mismas fechas en la fábrica de abonos "Cros", donde los enlaces habrían ido a primero a hablar con el gobernador $y$, "hartos de que se les engañase" y dispuestos a entregar sus credenciales, habrían amenazado con "ir a Madrid a hablar con el ministro y si no conseguían lo que pedían tomar sus medidas", es decir, ir a la huelga (nota 44).

En algunos casos señalados, los intentos gironistas de captación de antiguos dirigentes de la CNT habrían tenido éxito y se guarda una positiva apreciación individualizada de estos comportamientos en el testimonio de los obreros de astilleros. En este caso, el documento oral da la medida de la percepción despolitizada, en claro contraste con las sesgadas alusiones comunistas a estos casos (nota 45). También 


\section{J. Alberto Gómez Roda}

el análisis de los documentos orales permite medir los límites de la percepción positiva de este Girón mítico (nota 46).

\section{La escuela y la socialización fascista y católica}

\section{Escuela... o "no escuela"}

La percepción de la institución escolar entre muchos hombres y mujeres de origen popular y obrero es más bien la "no escuela", debido al elevado absentismo escolar y al temprano inicio de la vida laboral de los niños de la posguerra por la necesidad de contribuir a la subsistencia familiar. El gobernador Laporta emprendió, desde 1944, campañas contra el absentismo escolar, y en un informe comunista leemos: "Hay un gran número de niños vagabundos e incluso de rateros. La escuela oficial no llega a penetrar la mentalidad de la mayoría de los niños que sufren las consecuencias de la miseria y son orientados y educados por sus familiares" (nota 47). Para estos comunistas, irónicamente, la situación económica "había resuelto" el problema de calzar, vestir y educar a los hijos del obrero: “... les queda la tranquilidad de conciencia, de pensar que sus hijos no van a la escuela, porque no se puede pagar, de que no llevan zapatos porque no se pueden comprar, etc" (nota 48). 
Percepciones de las instituciones y actitudes políticas de la sociedad en la posguerra

Además de las dificultades económicas como obstáculo para la formación, otro lugar común en estos informes es la inutilidad de las enseñanzas sobrecargadas de contenidos religiosos, percepción consecuente con una idea secularizada de la inutilidad práctica de la religión: "Todos los hijos de los trabajadores en Valencia hacen las ocupaciones más bajas, expuestos en las calles a toda clase de perjuicios, casi ninguno ha pisado una escuela en su vida, no saben ni firmar, y los pocos que sus padres sacrificándose los han mandado, a los dos o tres años, aburridos, tienen que dejarla porque no les enseñan más que a rezar. Los únicos que pueden crearse una mediana cultura son los que pueden pagar una escuela particular, que no está al alcance de los trabajadores" (nota 49). Adquirir una especialización profesional sería difícil para los hijos de obreros pues no habría "posibilidades de ir a la Universidad o Academia por los elevados precios". En un informe de 1947 leemos: "Yo escuchaba últimamente las protestas de un maestro de la provincia de Teruel que enviaba a su hijo a Valencia y que sólo el ingreso en la Universidad para el $1^{\circ}$ de B[achillerato] le costaba 300 pts., aparte de los gastos de libros, estancia (en casa de unos familiares gratis) etc. Por cierto, entre los libros del primer año había un volumen de unas 200 páginas que era 'Explicación razonada del Catecismo" (nota 50). Los informes comunistas 


\section{J. Alberto Gómez Roda}

se hacían eco, en particular, de los profesionales depurados y expulsados o desterrados por motivos políticos de Colegios e instituciones de enseñanza, de su degradación laboral y de sus dificultades para encontrar empleo: "la consigna era cercarlos por el hambre, el aislamiento y el sufrimiento moral." El recurso más habitual habría sido, "mientras no los han localizado, la enseñanza particular." Las instituciones de enseñanza y cultura estarían, como resultado de la depuración, ocupadas por un personal adicto al régimen que habría llegado "al profesorado y hasta a la cátedra 'por motivos de guerra' sin terminar ni siquiera los estudios" (nota 51).

\section{Frente de Juventudes}

Fuera de las escuelas, donde la asistencia de los hijos de las clases populares era breve e irregular, y de algunas obligaciones administrativas de afiliación, el Frente de Juventudes ganaba prosélitos por su oferta de tiempo libre. A finales de los años 40 se percibía una presencia muy disminuida del mismo en los medios obreros, sólo escasamente superada por las juventudes católicas. Se le reconocían algunos éxitos que se atribuían a ciertos alicientes en un mar de carencias: "En las barriadas, los jóvenes son buscados para las centu- 
Percepciones de las instituciones y actitudes políticas de la sociedad en la posguerra

rias de Falange con el aliciente de las excursiones y otras pequeñas cosas, y algo de comida" (nota 52). Otro informe de 1949 decía, en cambio, que "en Valencia al principio algunos jóvenes por miedo se apuntaron en el Frente de Juventudes, pero que ahora son motivo de risa más que de otra cosa y que no movilizan más que a una porción ínfima de la juventud" (nota 53). Elisa Carrio, en 1949, aportaba una percepción similar: "Acción Católica tiene una gran actividad, buscando dinero para Navidades, templos, etc. Las filas de Falange no son numerosas. Cuando se ve alguna camisa falangista es en algún muchacho. El franquismo halaga mucho a la juventud 'pero no se deja ganar'. En la Calle de la Paz han puesto una casa con billares y otras distracciones pero sólo se ven algunos muchachos" (nota 54).

\section{La Iglesia católica, el anticlericalismo y la contradicto- ria religiosidad popular. La Acción Católica}

Los documentos comunistas están teñidos en sus percepciones sobre la Iglesia católica de un fuerte anticlericalismo que solamente encuentra correspondencia en la agresividad de la propia institución eclesiástica, imbuida del espíritu de cruzada de la guerra civil. Sólo esta Iglesia agresiva con su política de re-catolización es comparable en sentido y alcan- 


\section{J. Alberto Gómez Roda}

ce con el fascismo en el afán del mismo por nacionalizar la vida social y privada de los ciudadanos. Era el resultado de una actitud anacrónica, opuesta al respeto a la religiosidad perteneciente al ámbito de la libre soberanía privada del individuo. Como en territorio pagano sin evangelizar, la Iglesia organizó misiones que ilustran esta agresividad invasiva y su clara ubicación en el carro de los vencedores. La Iglesia de la posguerra, lejos de emotivas adhesiones ciegas, daría así lugar a un complejo campo de percepciones contradictorias, desde el caso del católico practicante maltratado por el régimen que había desarrollado sentimientos anticlericales, hasta la socialización católica del hijo de republicano sin obstáculo alguno debido al silencio o "ausencia política" simbólica del padre (nota 55). En general, la generación que había hecho la guerra estaría más condicionada que los jóvenes, entre quienes la Acción Católica con sus ramificaciones pudo aprovechar que era "quizás la única sociedad colectiva que en España funciona; al margen de Falange".

De la Acción Católica nos llega en el informe de Irene Conesa de 1952 una doble percepción, como organización centrada en la "organización de Congresos Eucarísticos, Conferencias Espirituales, Ejercicios, Catequesis, 'caridades', etc.", con una importante militancia femenina - "tanto 
Percepciones de las instituciones y actitudes políticas de la sociedad en la posguerra

en Valencia como en los pueblos, se ven bastantes insignias de Acción Católica sobre todo entre las mujeres y muchachas, que por sus vestimentas deben ser dependientas, empleadas, e hijas de la clase media"-, y como entidad capaz de ofrecer espacios de comunicación y sociabilidad: "De Acción Católica hay en casi todos los pueblos un local que llaman Casino, Círculo o Centro Católico. Tienen bebidas y juegos y sobre todo en pueblos pequeños como Alboraya y otros de este tipo se encuentran muy concurridos por las noches, aparentemente no tienen ningún fin de propaganda política. Parece que tienen por objeto el concentrar a los obreros del pueblo, controlar su actividad, y hacerles perder el tiempo de que disponen después del trabajo que los activistas de Acción Católica realizan en el seno de estas tertulias que se forman (sic)". Respecto a las HOAC, Conesa escribía: "... la sola actividad que se conoce de este tipo es la que realizan unas que se llaman Damas Catequistas y que visitan a los obreros parados o en grandes dificultades, para dar limosnas, preocuparse de los casamientos y los bautizos e invitarles a conferencias que suelen dar que, no tienen aparentemente más que un contenido religioso, pero entre el que entremezclan el social" (nota 56). 


\section{J. Alberto Gómez Roda}

\section{Jóvenes, ocio y sociabilidad}

La anterior referencia a los centros de la Acción Católica como ámbito popular de sociabilidad nos permite introducir una de las conclusiones importantes de la investigación sobre la Valencia de la posguerra. Esta es la del éxito de las ofertas de ocio y de los ámbitos de convivencia donde estuviese ausente la política como podían ser los propios centros católicos, el mundo fallero o las bandas de música (nota 57).

Frente al escaso éxito de las formas institucionales orientadas a los jóvenes se percibía en 1949 una cultura popular nutrida por "la literatura folletinesca, el cine y los deportes" como "válvulas de escape por donde la juventud da salida a sus energías" (nota 58). Elisa Carrio se refería sobre todo al cine: "Hay muchos espectáculos sobre todo cine y va bastante gente. Ella iba al cine porque 'con dos pesetas' nada puedes hacer y prefería gastarlas en divertirme" (nota 59). En 1952 llamaban la atención de Irene Conesa la existencia de "una verdadera profusión de novelas, que la gente lee, de una serie que se titula F.B.I.", y de bibliotecas ambulantes de préstamo donde podían "alquilarse".

La cultura de los jóvenes de la clase trabajadora sería por tanto de evasión, refractaria a las ofertas de instituciones que tuviesen relación con alguna militancia. No se trataría de 
Percepciones de las instituciones y actitudes políticas de la sociedad en la posguerra

una resistencia política, al menos explícita. Más bien al contrario. En 1955 parecía existir un abismo insalvable entre la cultura política y percepciones de la generación que hizo la guerra civil y las de los jóvenes, indiferentes a las críticas políticas de los viejos comunistas sobre las penurias de la posguerra. Los jóvenes habrían perdido por entero la perspectiva de un cambio político o de otra situación política posible y hacían suya la realidad cotidiana en la que vivían: no percibían que pudiera ser peor que la que habían vivido sus padres. Es más, el silencio político y la autocensura de los padres habría permitido que se hiciesen hueco en sus mentes las imágenes demoníacas lanzadas sobre los rojos en púlpitos y escuelas. De ahí que nuestro informante no dejase de repetir: "la formación política les envenena". ¿Un éxito del régimen?

Difícilmente puede considerarse un éxito una cultura de la retracción y del miedo, primero, de la evasión después, resultado de un comportamiento institucional que creó un abismo entre el aparato institucional del "Nuevo Estado" y la sociedad civil con efectos perniciosos de larga duración. Si su objetivo era el ideal fascista de romper la cesura creada por el liberalismo entre el Estado y la sociedad, e integrar a los ciudadanos movilizados en la empresa del Estado mítico, 


\section{J. Alberto Gómez Roda}

con un líder que encarnase a la nación, difícilmente podría haberse llegado a ir más lejos en la dirección opuesta. En palabras de Borja de Riquer, se creó una profunda divisió, un clar trencament polític, entre el mon oficial i el que podríem anomenar la societat civil. L'Estat, l'administració pública a tots els seus nivells, era el dels guanyadors de la guerra, i no tractava de la mateixa forma a tots els ciutadans (nota 60). El estado franquista fue el de los vencedores, represivo y desmovilizador, terrorista y revanchista, contrario a los derechos de los trabajadores, de las mujeres y de las nacionalidades no españolas del mismo. Esta valoración parte de suponer, como hacían los comunistas, que la mayoría de la "gente común", si se hubiese "significado", lo hubiese hecho en sentido antifranquista. Pero lo que nos enseñan los informes del PCE es que ellos mismos pudieron percibir la radical despolitización, el aislamiento en el que se movían. No quiere ello decir que faltase el "suelo" o sustrato para actitudes de resistencia, más bien ambigua, pasiva y evasiva, ni que no existiese una base o núcleo de manifiesta adhesión a la dictadura, pero una amplia "re-politización" de la gente común tardaría aún dos o tres décadas en producirse y sería distinta a la de los años 30 . Pero éste ya es otro tema. 


\section{Percepciones de las instituciones y actitudes políticas de la sociedad en la posguerra}

1. Este artículo se basa en la investigación realizada para un proyecto colectivo dirigido por Ismael Saz que tuvo una primera publicación de resultados en el libro El franquismo en Valencia. Formas de vida $y$ actitudes sociales en la posguerra, Valencia, 1999.

2. SAZ, Ismael, "Trabajadores corrientes. Obreros de fábrica en la Valencia de la posguerra”, en SAZ, Ismael y GómEZ, Alberto (eds.), El franquismo en Valencia. Formas de vida y actitudes sociales en la posguerra, Valencia, 1999, p. 231

3. Ramírez, Manuel, España 1939-1975 (Régimen político e ideología), Barcelona, 1978, pp. 112-117. Cfr. MALEFAKIS, Edward, "La dictadura de Franco en una perspectiva comparada", en Fusı, Juan Pablo y otros, Franquismo. El juicio de la historia, Madrid, 2000, en particular la p. 26, donde Malefakis escribe lo siguiente: "Hubo una tendencia a la corrupción masiva durante los años cuarenta, los años del hambre y del estraperlo, pero no rebasó ciertos límites y, durante la mayor parte de la época franquista, la corrupción oficial no parece haber sido un problema más grave de lo que lo es en la mayoría de los regímenes dictatoriales o democráticos. El acto más censurable del régimen fue la salvaje represión que aplicó tras su victoria en la Guerra Civil, pero lo hizo con la aquiescencia o el apoyo de muchos sectores de la sociedad, y de acuerdo con la opinión ampliamente compartida de que era en interés público, no a causa de la depravación personal de los principales líderes franquistas”.

4. Peukert, Detlev, Inside Nazi Germany. Conformity, Opposition and Racism in Everyday Life, Londres, 1987 (edic. original 1982). 


\section{J. Alberto Gómez Roda}

5. Dirigió el proyecto Ismael Saz e intervinieron Alvaro Alvarez, Joan Adrià, Gil Manuel Hernández, Ramiro Reig, Daniel Simeón y Alberto Gómez.

6. Véase la memoria de los soldados marroquíes y de la ocupación militar en ADRIÀ, Joan J. , "Los factores de producción de consentimiento político en el primer franquismo: consideraciones apoyadas en el testimonio de algunos lirianos corrientes", en SAZ, Ismael y GómEZ, Alberto (eds.), El franquismo en Valencia..., pp. 117-158.

7. "Informe de Tuñón", París, 26 de noviembre de 1946. AHPCE, Informe del Interior no 95, sign. 121-126. "Informe de Julio Marco Orts, de Valencia”, 26 de diciembre de 1949. AHPCE, Informe del Interior no 21, sign. 25. Julio Marco era hijo de Vicente Marco Miranda, fundador del partido republicano nacionalista Esquerra Valenciana.

8. "Biografía e informe de M. González Bastante sobre la situación en España”, 10 de octubre de 1946. AHPCE, Informe del Interior no 150, sign. 183-186.

9. Ibídem. Véase además "Informe de Julio Marco Orts, de Valencia".

10. SAZ, Ismael, "Trabajadores corrientes. Obreros de fábrica en la Valencia de la posguerra", en SAZ, Ismael y GómEZ, Alberto (eds.), El franquismo en Valencia..., pp. 198 y 229.

11. "Información de Ángel Gaos González-Pola sobre la situación en España”, 31 de noviembre de 1946. AHPCE, Informe del Interior № 175, sign. 223-224. 


\section{Percepciones de las instituciones y actitudes políticas de la sociedad en la posguerra}

12. Conxita Mir ha investigado redes locales de parentesco y clientelares implicadas en la represión militar, demostrando su importancia y extensión. Mır, Conxita, Vivir es sobrevivir. Justicia, orden y marginación en la Cataluña rural de posguerra, Lleida, 2000, en particular pp. 251 y ss.

13. En los documentos de los primeros años 50 se refieren incidentes de resistencia anónima a la violencia arbitraria de algún policía o falangista, habitualmente en tranvías.

14. AGA, Interior, Gobierno Civil de Valencia, Orden Público, Caja 3653, Leg. 4, Exp. 26.

15. "En Madrid, el jornal base es de 12 pesetas más el 25\% de 'carestía de vida'. Pero después de pagar el 'seguro de enfermedad', el 'subsidio familiar' y la 'cuota sindical', le quedan al obrero 14'12 ptas. (...) Todos pasan hambre y calamidades a excepción de los guardias civiles y los de la Policía Armada; estos, además del sueldo y el $25 \%$ de 'carestía de vida' tienen pluses, racionamiento especial y 'manga ancha para hacer estraperlo". "Informe de Antonio y Tomás Sanz Calleja sobre la situación en España", 15 de agosto de 1948. AHPCE, Informe del Interior no 141, sign. 174.

16. "Informe de Simón Díaz Sarro, Secretario General del Comité Provincial del PCE en Valencia", 25 de junio de 1949. AHPCE, Informe del Interior no 7, sign. 8-9.

17. "Informe de José Pareja Garrido", abril 1952. AHPCE, Serie Microfilms "Levante", jacquet 691-692. 


\section{J. Alberto Gómez Roda}

18. Fundación Nacional Francisco Franco, Documentos Inéditos para la Historia del Generalísimo Franco, Tomo II-2, Madrid, 1992, no 180, 25 de agosto de 1941, "Primer informe de Carrero Blanco sobre la situación interior en España”, al ser nombrado subsecretario de la presidencia, pp. 316-331.

19. "Situation in Valencia. From Consul Mead e. (Valencia) to $\mathrm{Mr}$ Stevens", 24 de octubre de 1939. FO 371/24132/31357, W12462/8/41.

20. "Sir S. Hoare to Mr. Eden", 5 de enero de 1942. FO 371/31234/31388, C 514/220/41.

21. "Información de Ángel Gaos González-Pola...".

22. Jefatura Provincial de FET y de las JONS de Valencia, Parte mensual de agosto de 1941, AGA, DNP, C. 67.

23. Jefatura Provincial de FET y de las JONS, Conferencias. Cursillo de Perfeccionamiento para Jefes Locales y Alcaldes, Valencia, 1945, pp. 145-147.

24. “Informe de Joaquín Martínez Gonzalvo ‘Chimi’ sobre Valencia”, 9 de junio de 1949. AHPCE, Informe del Interior, sign. 4.

25. "Situation in Spain", sumario sobre la situación en España obtenido de la censura de correspondencia, 6 de enero de 1939. FO $371 / 24507 / 31357$, C 668/40/41.

26. "Informe de Luis Alvar González...". 


\section{Percepciones de las instituciones y actitudes políticas de la sociedad en la posguerra}

27. "Informe de Irene Conesa sobre la situación general en Valencia", marzo 1952. AHPCE, Serie Microfilms "Levante", jacquets 722-723.

28. "Información facilitada por (1)", 3 de agosto de 1955. AHPCE, País Valenciano, caja 77, Carpeta 2/2.

29. "Informe de Vicente Galiana Serra sobre la situación en España", 8 de julio de 1946. AHPCE, Informe del Interior no 188, sign. 242.

30. La medida se había convenido en una reunión de los Inspectores de la Comisaría de Recursos, el Jefe Provincial del Trigo y la Junta Local de Recursos. AGA, Interior, Gobierno Civil de Valencia, Orden Público, Caja 3654, Leg. 8, Exp. 54.

31. "Informe de Irene Conesa...".

32. "Biografía e informe de Manuel González Bastante...".

33. Ibídem.

34. "Informe de Joaquín Martínez Gonzalvo...".

35. "Biografía e informe de Manuel González Bastante...".

36. "Elisa Carrio", 23 de septiembre de 1949. AHPCE, Serie de Microfilms 'Levante', jacquets 592-593.

37. "Información facilitada por (1)...".

38. "Biografía e informe de Manuel González Bastante...".

39. "Informe de Manuel Pérez sobre la situación en España", 12 de febrero de 1949. AHPCE, Informe del Interior no 144, sign. 177. 


\section{J. Alberto Gómez Roda}

40. "De las conversaciones tenidas con Escrich", mayo de 1949. AHPCE, Serie de Microfilms de "Levante", jacquets 591.

41. "Elisa Carrio...".

42. Sobre la política laboral del franquismo en la posguerra, véase la obra de BABIANO, José, Paternalismo industrial y disciplina fabril en España (1938-1958), Madrid, 1998.

43. "Informe de Irene Conesa...".

44. "Levante. Informe de Jacinto, sobre su viaje a Valencia (abril de 1952)". AHPCE, Microfilms Levante, jacquets 693-694.

45. “Entre la CNT hay discusión [sobre el ‘pacto Franco-americano' de 1953], producto de que algunos son indondicionales del régimen. Girón tiene entre ellos muy buenos amigos. Girón les ha facilitado dinero, con lo que han creado una fuerte casa de Seguros". "Informe de Antonia", 13 de mayo de 1953. AHPCE, Serie Microfilms "Levante", jacquet 782 .

46. Véase en detalle SAZ, Ismael, "Trabajadores corrientes...”, pp. 187233.

47. "Informe de Vicente Galiana Serra sobre la situación en España", 8 de julio de 1946, AHPCE, Informes del Interior no 188, sign. 242.

48. "Biografía e informe de Manuel González...".

49. "Informe de José Pareja Garrido...".

50. "Información facilitada por Luis Delege...".

51. "Biografía e informe de Manuel González...". 
Percepciones de las instituciones y actitudes políticas de la sociedad en la posguerra

52. "Información facilitada por Luis Delege...".

53. "Informe de Joaquín Martínez Gonzalvo...”.

54. "Elisa Carrio...".

55. Véase AlvareZ, Álvaro, "Los católicos en el primer franquismo. La vida cotidiana en el barrio del Botánico de Valencia", en SAZ, Ismael y Gómez, Alberto (eds.), El franquismo en Valencia..., pp. 259-284.

56. "Informe de Irene Conesa...".

57. Véase sobre los católicos el trabajo de Álvarez, Álvaro, "Los católicos en el primer franquismo, ...", y sobre las fallas el de HERNÁNDEZ, Gil-Manuel, "Una mirada sobre el mundo fallero", en SAZ, Ismael y Gómez, Alberto (eds.), El franquismo en Valencia ... , pp. 235-258 y 259-284 respectivamente. Puede verse también el caso de las bandas de música de Llíria en ADRIÀ, Joan J., "Los factores de producción de consentimiento...", en Ibídem, pp. 156-157.

58. "Informe de Simón Díaz Sarro...”.

59. "Elisa Carrio...".

60. RIQUER, Borja de y CULLA, Joan Baptista, El franquisme i la transició a la democràcia (1939-1988), Barcelona, 2000 (edic. original 1989), p. 134. 